\title{
Aspire to be smoke-free pilot study: A prevention educational outreach serving preschool children in rural Arkansas
}

\author{
Lana Gettman', Gabriella A. Douglass' ${ }^{1}$, Madison Wessel' , Julie Kissack ${ }^{1}$
}

\section{Dear Editor,}

This letter describes an innovative pilot project providing community outreach education to preschool children about the dangers of cigarette smoking. Arkansas youth use tobacco at higher rates compared to the US youth smoking rate, which has significantly declined in recent years ${ }^{1}$. The initiation of cigarette smoking during childhood and adolescent years increases the risk of life-long nicotine dependence. Education efforts aimed at empowering youth to say no to smoking have the potential to affect health outcomes ${ }^{2}$.

Lower socioeconomic status and lower education levels are risk factors correlated to high smoking prevalence ${ }^{3}$. Government-funded Head Start Programs provide education and other assistance to low-income preschool children and their families. The purpose of the pilot study was to examine the impact of a brief educational program on the hazards of cigarette smoking in preschool children, aged 3-5 years, enrolled in Arkansas Head Start Programs.

The study was approved by the Institutional Review Board. It was funded by the Arkansas Cancer Coalition and completed at select Arkansas Head Start Program facilities located in rural areas of central Arkansas.

The pre-post study design was used to evaluate the effectiveness of the educational program. Under the supervision of a pharmacist faculty, a team of third-year pharmacy students delivered a brief multi-modal interactive educational program on the hazards of cigarette smoking. An illustration of a healthy versus a rotten apple was used to explain the difference between a healthy lung and a lung exposed to cigarette smoke. A respiratory system model provided a hands-on learning experience demonstrating the differences in the elastic recoil of a healthy versus a damaged lung. An anatomical model of a buccal cavity was also used to demonstrate the damage of cigarette smoke on teeth and mouth. Assessment of understanding took place before and after the education program by asking participants to raise their hands if they thought smoking was bad for their health.

During two months, the team traveled to five Head Start locations in three counties of central Arkansas. Ninety-two preschool children's responses were collected. The pre and post responses indicated an increase of knowledge. Fifty-seven (61\%) children knew that smoking was harmful to a person's health before program delivery compared to $78(84 \%)$ children after education.

This pilot study describes a collaborative effort between an academic setting and a government-funded program to deliver smoking prevention education to a preschool audience. The children's improved knowledge about the dangers of smoking from the intervention could empower them to avoid cigarette smoke in their lives. Limitations of the pilot study include the rural location, short period, and small sample size. A study of longer duration with larger sample size
AFFILIATION

1 College of Pharmacy, Harding University, Searcy, United States

CORRESPONDENCE TO

Lana Gettman. College of Pharmacy, Harding University, Searcy, AR 72143, United States. E-mail: Igettman@harding.edu

\section{KEYWORDS}

children, prevention, smoking, preschool

Received: 24 June 2019 Revised: 22 November 2019 Accepted: 29 November 2019 
is needed to clarify the impact of this type of intervention. Future projects could build on the data that were collected during this pilot project.

\section{REFERENCES}

1. Centers for Disease Control and Prevention. Extinguishing The Tobacco Epidemic in Arkansas. https://www.cdc.gov/ tobacco/about/osh/program-funding/pdfs/arkansas-2018-508.pdf. Updated April 5, 2018. Accessed September 14, 2018.

2. National Center for Chronic Disease Prevention and Health Promotion (US) Office on Smoking and Health. The Health Consequences of Smoking-50 Years of Progress: A Report of the Surgeon General. Atlanta, GA: Centers for Disease Control and Prevention; 2014.

3. Hiscock R, Bauld L, Amos A, Fidler JA, Munafo M. Socioeconomic status and smoking: a review. Ann NY Acad Sci. 2012;1248(1):107-123. doi:10.1111/j.1749-6632.2011.06202.x

\section{ACKNOWLEDGEMENTS}

We thank the Arkansas Cancer Coalition for financial support and the Arkansas Head Start Program for coordinating available times in their program for our prevention education program. We also thank Megan Vaden and Quynh-Nhu Huynh for their assistance with project design and data collection.

\section{CONFLICTS OF INTEREST}

The authors have each completed and submitted an ICMJE form for disclosure of potential conflicts of interest. The authors declare that they have no competing interests, financial or otherwise, related to the current work. L. Gettman, G. A. Douglass, M. Wessel and J. Kissack report grants from Arkansas Cancer Coalition, during the conduct of the study.

FUNDING

The research was supported by the Arkansas Cancer Coalition.

PROVENANCE AND PEER REVIEW

Not commissioned; externally peer reviewed. 